\title{
Age of the Tananwan Formation in Northern Taiwan: A Reexamination of the Magnetostratigraphy and Calcareous Nannofossil Biostratigraphy
}

\author{
Chorng-Shern Horng * \\ Institute of Earth Sciences, Academia Sinica, Taipei, Taiwan, Republic of China
}

Received 27 August 2013, accepted 5 November 2013

\begin{abstract}
Over the past two decades, the succession strata of the Tananwan Formation exposed horizontally on the Linkou Tableland in northwestern Taiwan has been either dated to a short time interval of 0.9 - $0.7 \mathrm{Ma}$ or assigned to a vague long period within the Matuyama Epoch covering probably both the Olduvai and Jaramillo normal events. In this study, a reexamination of magnetostratigraphy and calcareous nannofossil biostratigraphy of this formation was carried out. The results show that the strata with stable remanent magnetizations have reversed magnetic polarities only, and the layers with marine sedimentary facies consistently contain specimens of large Gephyrocapsa. These updated results suggest that the Tananwan Formation was deposited within the interval of 1.46 - 1.24 Ma, corresponding to a short period of reversed magnetic polarity of the Matuyama Epoch.
\end{abstract}

Key words: Tananwan Formation, Magnetostratigraphy, Nannofossil, Siderite

Citation: Horng, C. S., 2014: Age of the Tananwan Formation in northern Taiwan: A reexamination of the magnetostratigraphy and calcareous nannofossil biostratigraphy. Terr. Atmos. Ocean. Sci., 25, 137-147, doi: 10.3319/TAO.2013.11.05.01(TT)

\section{INTRODUCTION}

The Tananwan Formation, exposed on the Linkou Tableland in northwestern Taiwan, is characterized by its flat-lying strata consisting of loosely cohered sandstones and mudstones intercalated with conglomerates (Figs. 1a and 2a, c, d). Sedimentary facies analysis indicates that these sediments were deposited in nearshore environments with shallow water marine, beach, lagoon, tidal, delta, lacustrine, fluvial and alluvial lithofacies (Chen and Teng 1990; Chuang et al. 2012). Overlying the Tananwan Formation is the Linkou Formation composed of thick or massive conglomerates. This lithofacies change was due to uplifting episodes of northern Taiwan during the Plio-Pleistocene Penglai Orogeny.

To reconstruct the tectonic history of the Penglai Orogeny, it is important to understand the chronology of uplifting events. Over the past two decades, methods including electron spin resonance, pollen, magnetostratigraphy and calcareous nannofossil have been used to construct a more detailed chronology of the Tananwan Formation. These studies claimed that the succession strata of the Tananwan Formation may represent a long period in the Matuyama Epoch most likely covering the Olduvai and Jaramillo normal events (Lee et al.

\footnotetext{
* Corresponding author

E-mail: cshorng@earth.sinica.edu.tw
}

2002), or a short time interval between 0.9 and $0.7 \mathrm{Ma}$ (Shih 1991; Tseng et al. 1992; Wei et al. 2009).

Regardless of this difference in the estimated age, ambiguous interpretations and conflicting observations exist among these studies. For the magnetostratigraphy, Lee et al. (2002) reported that most of the sites they surveyed in the Tananwan Formation had reversed magnetic polarity records, but some had abnormal paleomagnetic directions that were interpreted equivocally to be the Olduvai and Jaramillo normal polarity events in the Matuyama Epoch or to be disturbed by coarse sediments deposited in high-energy environments. These two interpretations contradict each other because the former one suggests a low sedimentation rate for the Tananwan Formation (i.e., $0.1 \mathrm{~mm} \mathrm{yr}^{-1}$, derived from a 80-m succession of strata with a time duration of about 0.8 million years, see Fig. 4 of Lee et al. 2002), whereas the latter one implies a dynamic setting with high and variable sedimentation rates.

Tseng et al. (1992) studied the calcareous nannofossil biostratigraphy of the Tananwan Formation and reported the presence of large Gephyrocapsa. According to Rio (1982) and Rio et al. (1990), the genus Gephyrocapsa Kamptner underwent morphologic evolution during the late PliocenePleistocene. This genus can be divided into four categories 
based on biometric definition: (1) small Gephyrocapsa (lumping all forms with sizes $<3.5 \mu \mathrm{m}$ ), (2) medium Gephyrocapsa $(4-5.5 \mu \mathrm{m})$, (3) large Gephyrocapsa $(>5.5 \mu \mathrm{m})$, and (4) Gephyrocapsa sp. 3 (> $4 \mu \mathrm{m}$, characterized by a bridge nearly parallel to the short axis of placolith). These four categories are useful for identifying subdivisions of the biostratigraphy based on their occurrence datum events whose ages have been dated and are shown in Fig. 2b (Rio 1982; Rio et al. 1984; Wei 1993; Berggren et al. 1995; Raffi et al. 2006). Despite Tseng et al. (1992) consistently finding specimens of large Gephyrocapsa in the Tananwan Formation, they did not assign an age of $1.46-1.24 \mathrm{Ma}$ (see Fig. 2b) to the formation. Instead, they proposed that the Tananwan Formation is younger than $0.9 \mathrm{Ma}$ according to their own pollen stratigraphy. In contrast, Wei et al. (2009) regarded the specimens of Gephyrocapsa in the Tananwan Formation as having sizes less than $5.5 \mu \mathrm{m}$ and morphologic features of Gephyrocapsa sp. 3. Together with other evidence such as the absence of Reticulofenestra asanoi, Wei et al. (2009) concluded that the age of Tananwan Formation is confined to $0.89-0.78 \mathrm{Ma}$. In an attempt to clarify whether the Olduvai and Jaramillo normal events suggested by Lee et al. (2002) are reasonable and to reconcile the differences regarding the sizes of Gephyrocapsa identified by Tseng et al. (1992) and Wei et al. (2009), a reexamination of magnetostratigraphy and calcareous nannofossil biostratigraphy of the Tananwan Formation is needed.

\section{MATERIALS AND METHODS}

Samples for paleomagnetic and nannofossil studies were collected along rivers or roads where outcrops of the Tananwan Formation are accessible (Fig. 1a). A total of 19 sites covering the entire Tananwan sequence were obtained from stratigraphic heights ranging from $c a .20$ to $150 \mathrm{~m}$ (Fig. 2a). At each site, 5 - 6 cores (25 $\mathrm{mm}$ in diameter) were

(a)

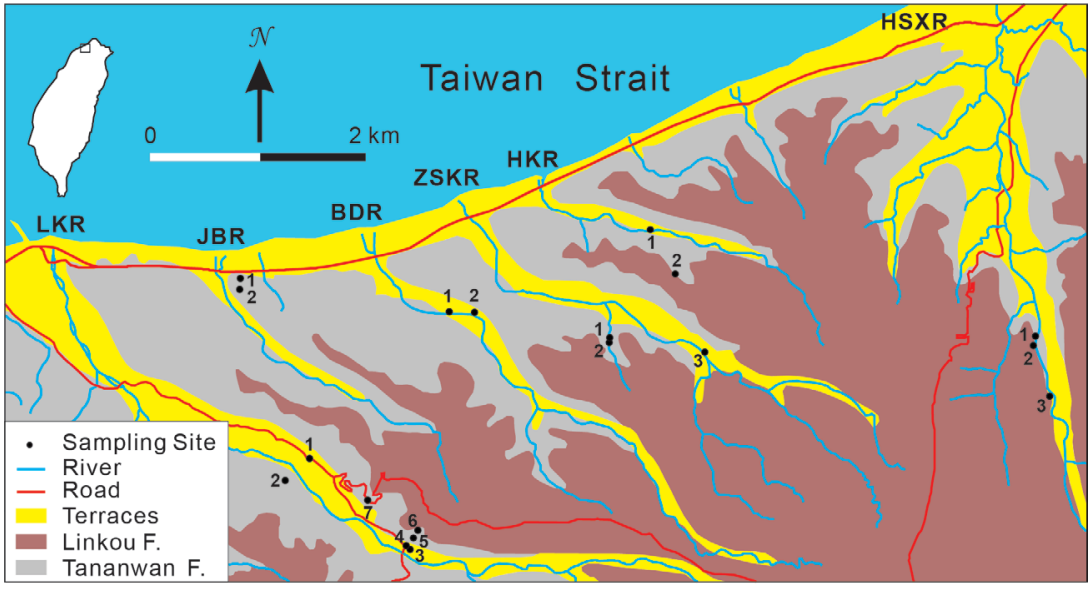

(b)

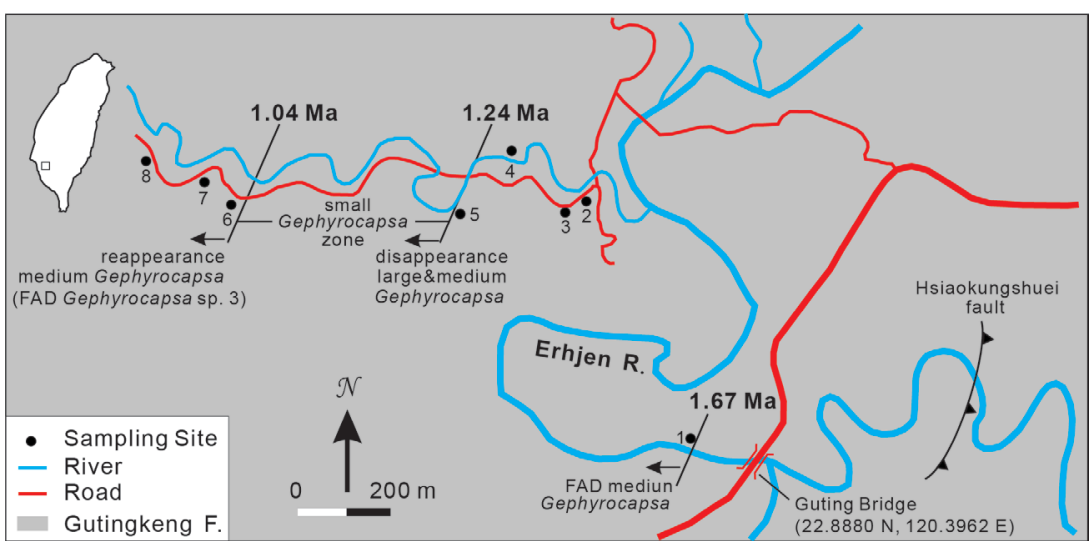

Fig. 1. (a) Map showing locations of 19 sampling sites in the Tananwan Formation on the Linkou Tableland in northwestern Taiwan. Samples were collected along rivers or roads. LKR, JBR, BDR, ZSKR, HKR, HSXR represent Linkou, Jiabao, Baodou, Zueishukeng, Houkeng, and Hongshuixian Rivers, respectively. (b) Map showing locations of 8 sampling sites in the Gutingkeng Formation of the Erhjen River (EJR) section in southwestern Taiwan. Ages of the strata are younger westwards with three well-dated calcareous nannofossil datum events indicated [1.67 Ma: the first appearance datum (FAD) of medium Gephyrocapsa; 1.24 Ma: the disappearance of large and medium Gephyrocapsa; 1.04 Ma: the reappearance of medium Gephyrocapsa or FAD of Gephyrocapsa sp. 3; Chen et al. 1977; Shea and Horng 1999; Raffi et al. 2006; Horng and Shea 2007]. During the time interval of $1.24-1.04 \mathrm{Ma}$, medium and large Gephyracapsa disappeared, and only small Gephyrocapsa survived. Thus, this interval is called the small Gephyrocapsa zone. 
(a)

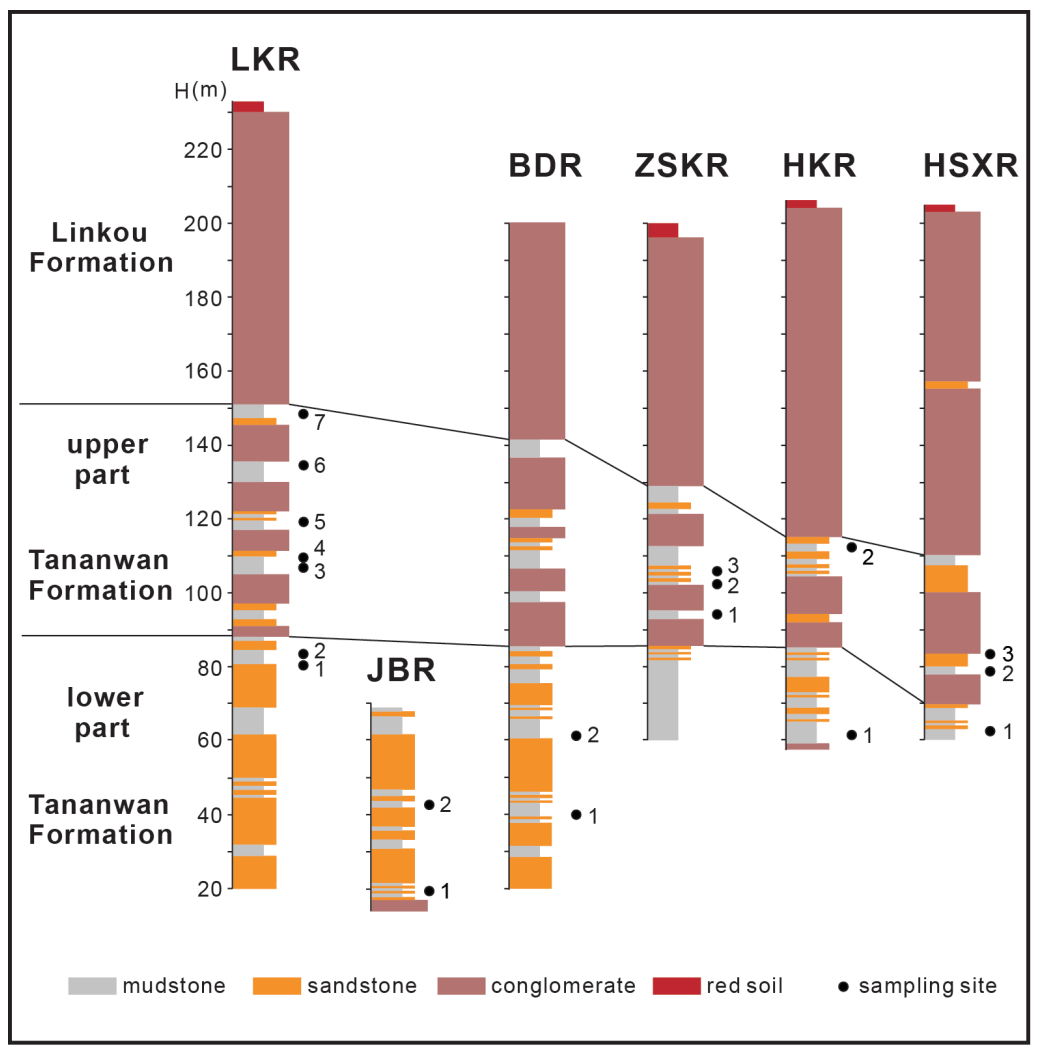

(b)

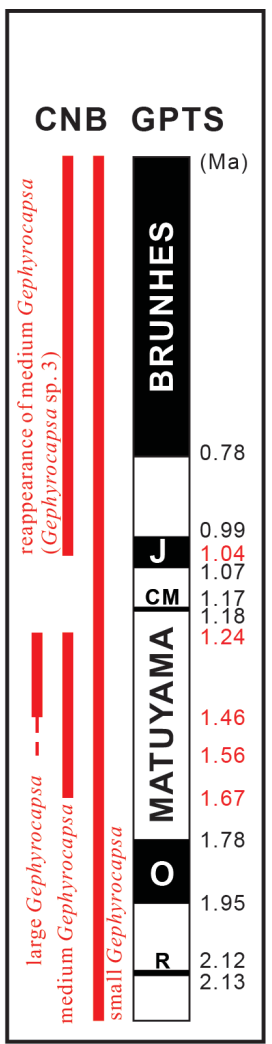

(c)

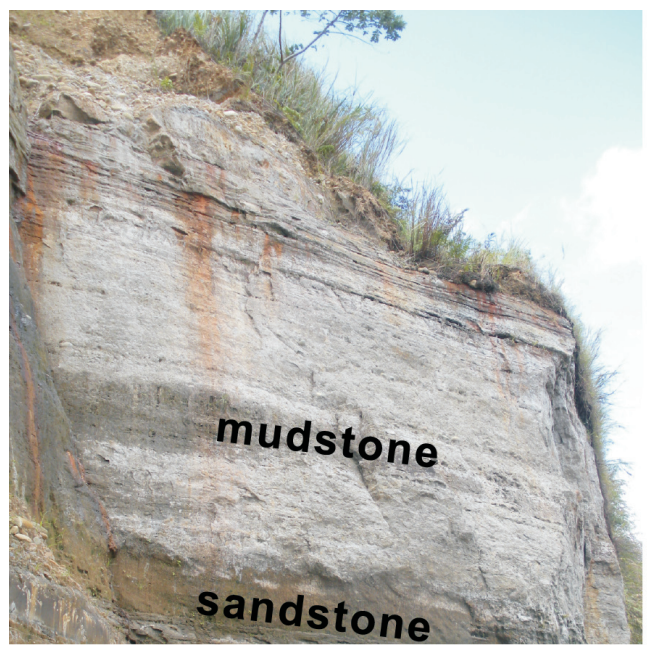

(d)

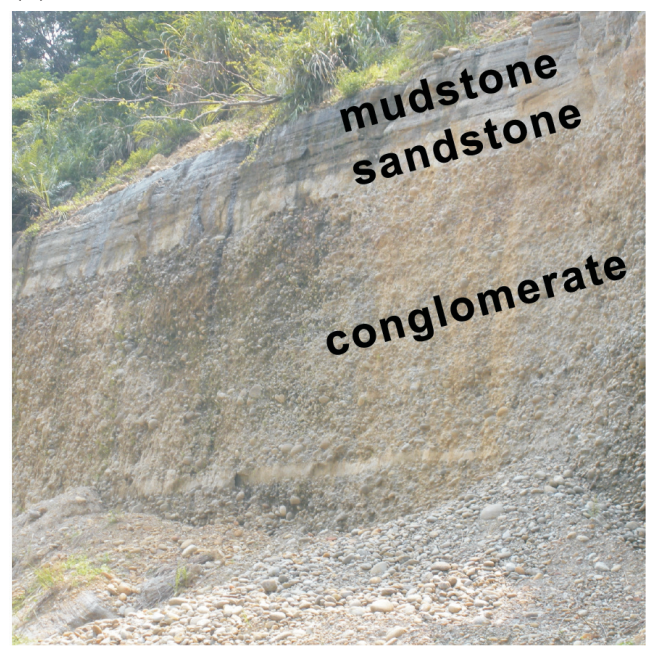

Fig. 2. (a) Stratigraphic profiles showing the Tananwan and the Linkou Formations and their lithological variations along six river (LKR, JBR, BDR, ZSKR, HKR, and HSXR) sections on the Linkou Tableland in northwestern Taiwan (after Chuang et al. 2012). The stratigraphic heights (H) of sampling sites on each section are indicated. (b) Geomagnetic polarity time scale (GPTS) and calcareous nannofossil biostratigraphy (CNB) of genus Gephyrocapsa since 2.2 Ma. Ages of Gephyrocapsa morphologic evolutional events are 1.67 Ma for the FAD of medium Gephyrocapsa, 1.56 Ma for the FAD of large Gephyrocapsa, 1.46 Ma for the onset of consistent occurrence of large Gephyrocapsa, 1.24 Ma for the disappearance of medium and large Gephyrocapsa, and 1.04 Ma for the reappearance of medium Gephyrocapsa (or the FAD of Gephyrocapsa sp. 3). Normal polarity events within the Matuyama reversed Epoch are Reunion (R), Olduvai (O), Cobb Mountain (CM), and Jaramillo (J) (Horng et al. 2002; Lourens et al. 2004; Raffi et al. 2006). (c - f) Field photos showing characteristics of the Tananwan Formation: (c) flat-lying sandstone and mudstone layers; (d) intercalation of conglomerate in mudstone and sandstone strata; (e - f) colors of siderite-bearing strata changed from dark gray to yellow or reddish brown depending on weathering extents. 
(e)

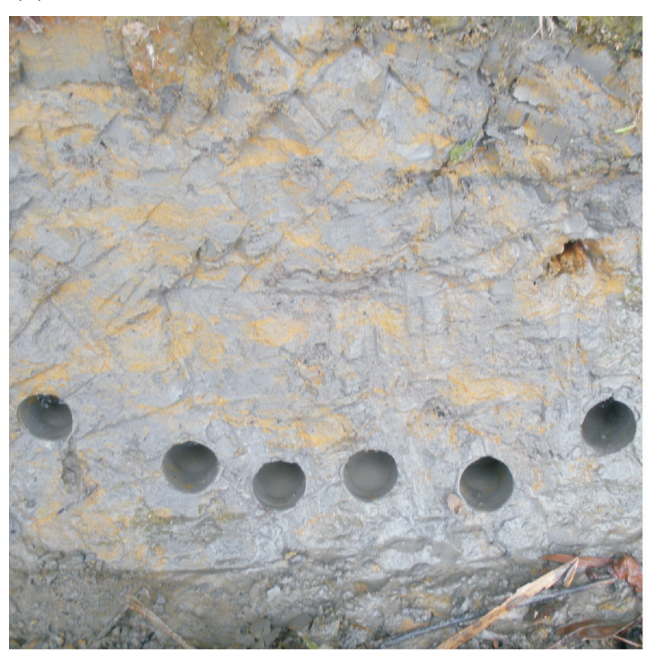

(f)

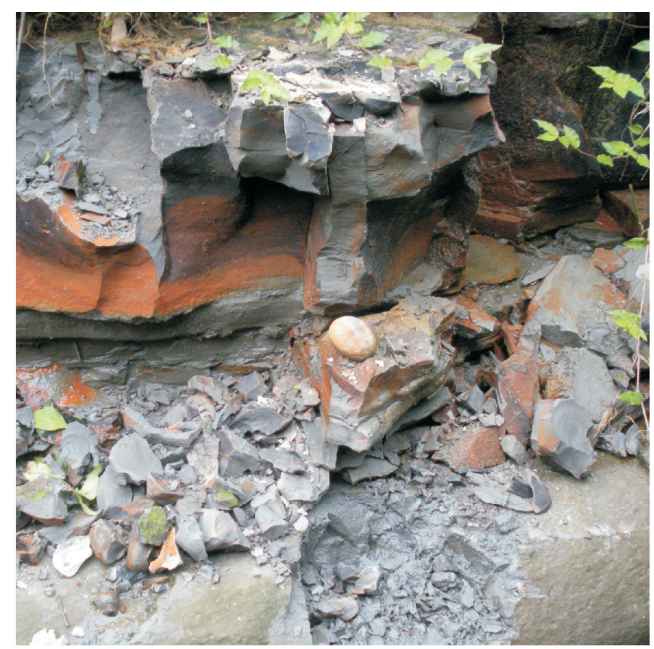

Fig. 2. (Continued)

drilled after removing weathered surface of outcrops. Cores were oriented (azimuth and dip) with a mechanical device mounted with a magnetic compass. Non-oriented samples were also taken from the sites for studying magnetic mineralogy and calcareous nannofossil biostratigraphy. Because the morphologic evolutional events of Gephyrocapsa are well preserved in the Gutingkeng Formation of the Erhjen River (EJR) section in southwestern Taiwan (Chen et al. 1977; Shea and Horng 1999; Horng and Shea 2007), samples from the EJR section straddling the stratigraphic levels from the first appearance datum (FAD) of medium Gepyrocapsa up to the post-FAD of Gephyrocapsa sp. 3 (Fig. 1b) were also collected for comparison with calcareous nannofossils in the Tananwan Formation.

In the laboratory, specimens (22 $\mathrm{mm}$ in length) were cut from oriented cores and then subjected to paleomagnetic analysis. For the natural remanent magnetization (NRM), specimens were measured with a $2 \mathrm{G}$ Enterprises superconducting rock magnetometer to obtain their intensities (J), declinations (Dec) and inclinations (Inc). Thermal demagnetization was then carried out by a Magnetic Measurements Ltd. thermal demagnetizer that has a low-field cooling chamber. Sixteen heating steps from room temperature up to $680^{\circ} \mathrm{C}$ were used (i.e., 25, 120, 160, 200, 240, 280, 320, 360, 400, $440,480,520,560,600,640$, and $680^{\circ} \mathrm{C}$ ) to obtain stable characteristic remanent magnetization $(\mathrm{ChRM})$ after erasing viscous and unstable secondary magnetizations. To monitor possible changes in magnetic minerals and magnetic properties during heating, low-field magnetic susceptibility $(\chi)$ was measured on specimens after each heating step with a Bartington Instruments MS2B magnetic susceptibility system. To characterize magnetic mineralogy in specimens and to interpret the behavior of remanent magnetizations during thermal demagnetization, magnetic separation from non-ori- ented samples using a rare earth magnet housed in a plastic sheath was used.

Low-temperature magnetic measurements and X-ray diffraction (XRD) analysis were carried out on magnetic extracts using a Quantum Design SQUID vibrating sample magnetometer (VSM) and a Rikagu Miniflex table top unit ( $\mathrm{Cu}-\mathrm{K} \alpha$ radiation), respectively. For the low-temperature magnetic measurements, magnetic extracts were cooled from room temperature to $5 \mathrm{~K}$ in zero field in the SQUID VSM. At $5 \mathrm{~K}$, a $5 \mathrm{~T}$ DC field was applied and then switched off to impart a low-temperature saturation isothermal remananet magnetization (SIRM). SIRM curves were measured during warming in zero field up to $300 \mathrm{~K}$ at a warming rate of $3 \mathrm{~K} \mathrm{~min}^{-1}$ to detect magnetic transitions revealed from magnetic extracts. Then X-ray scans were run from 4 to $80^{\circ}(2 \theta)$ to verify magnetic mineralogy suggested by SQUID VSM measurements. The results are presented after subtraction of the background.

Smear slides for nannofossil identification were prepared from small chips of non-oriented samples and then examined under an optical microscope and a scanning electron microscope (SEM). Observations were particularly focused on Gephyrocapsa spp. and their sizes were determined based on SEM images.

\section{RESULTS AND DISCUSSION}

\subsection{Magnetic Mineralogy}

Low-temperature magnetic measurements of magnetic extracts from the Tananwan Formation show that three magnetic transitions occur near 20,40, and $115 \mathrm{~K}$ upon warming of SIRM curves (Figs. 3a - b). The transition at $\sim 115 \mathrm{~K}$ is the Verwey transition that is a diagnostic feature of magnetite $\left(\mathrm{Fe}_{3} \mathrm{O}_{4}\right)$ at low temperatures (Verwey 1939; Özdemir 

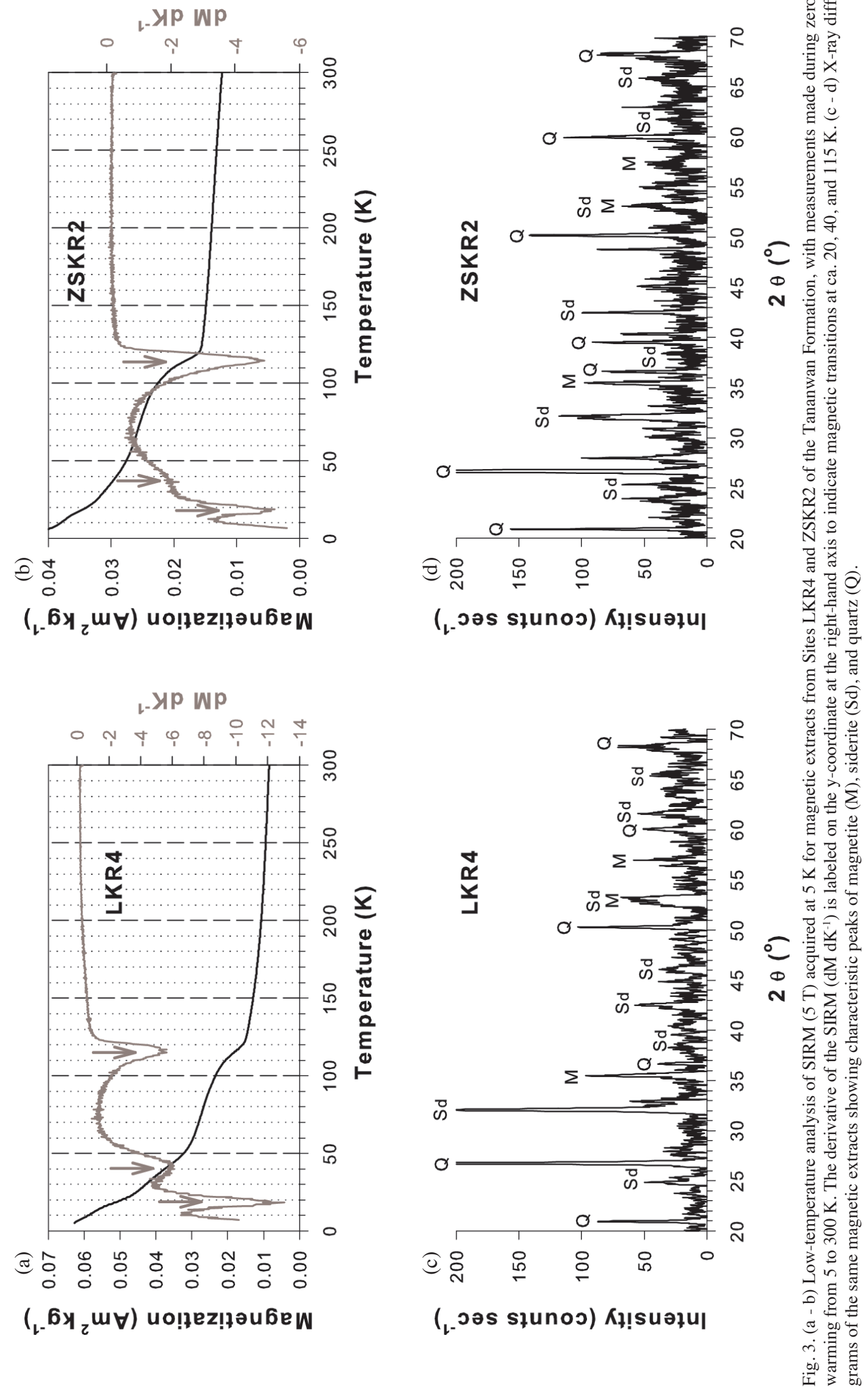
et al. 1993). For the transition at $\sim 40 \mathrm{~K}$, siderite $\left(\mathrm{FeCO}_{3}\right)$, pyrrhotite $\left(\mathrm{Fe}_{7} \mathrm{~S}_{8}\right)$ and rhodochrosite $\left(\mathrm{MnCO}_{3}\right)$ are three possible minerals causing the transition (Dekkers et al. 1989; Rochette et al. 1990; Housen et al. 1996). For the transition at $\sim 20 \mathrm{~K}$, however, no mineral responsible for it has been reported in literature, which is worthwhile to investigate in the future. XRD analysis on the magnetic extracts further confirms that magnetite and siderite are commonly present in the Tananwan Formation (Figs. 3c - d). Because siderite may form either in marine or in fresh-water environments (Mozley 1989; Pye et al. 1990), it is suggested that siderite in the Tananwan Formation was formed through diagenetic processes. Field observations show that siderite-bearing strata are susceptible to weathering. The oxidation of siderite to ferric iron minerals usually results in changes in rock color from dark gray to yellow or even reddish brown, depending on the extents of weathering (Figs. 2e - f).

\subsection{Magnetostratigraphy}

NRM intensity $\left(\mathrm{J}_{\mathrm{o}}\right)$ and low-field magnetic susceptibil- ity $\left(\chi_{0}\right)$ of Tananwan specimens before thermal demagnetization (i.e., at $25^{\circ} \mathrm{C}$ ) fall in the range of $2.8-155 \times 10^{-3} \mathrm{Am}^{2}$ and $8.9-36.1 \times 10^{-6}$, respectively (Table 1 ). The wide range of these values implies large variations in magnetic compositions and/or concentrations. The thermal demagnetization results from this study can be classified into two types, designated as Type $\mathrm{S}$ (stable) and Type $\mathrm{U}$ (unstable). The examples shown in Fig. 4 illustrate the behavior of the two types during thermal demagnetization treatments. In general, each Type $\mathrm{S}$ specimen has a rather stable remanence below $\sim 360^{\circ} \mathrm{C}$ and may slightly or dramatically change its remanent directions at higher temperatures (Figs. $4 \mathrm{a}-\mathrm{h}$ ). It is evident from Figs. $4 \mathrm{a}-\mathrm{h}$ that only reversed magnetic polarities were deciphered in Type $\mathrm{S}$ specimens according to their stable ChRMs (see Table 1). In contrast, Type U samples always show scattering and unstable remanences during thermal demagnetization. Among Type U, a few samples may have slightly scattering directions and still display a reversed magnetic polarity record (e.g., Fig. 4i), but most of Type $U$ samples are too unstable to decipher their magnetic polarities (Figs. $4 \mathrm{j}-1$ and Table 1).

Table 1. Characteristics of 19 sampling sites in the Tananwan Formation along 6 river sections (see Fig. 1a) and paleomagnetic properties revealed during thermal demagnetization treatments of the specimens.

\begin{tabular}{|c|c|c|c|c|c|c|c|c|c|c|}
\hline Site & Lat. $\left({ }^{\circ} \mathbf{N}\right)$ & Long. $\left({ }^{\circ} \mathbf{E}\right)$ & $\mathbf{H}(\mathbf{m})$ & Specimen & $\mathbf{J}_{0}\left(10^{-3} \mathrm{Am}^{2}\right)$ & $\chi_{0}\left(10^{-6}\right)$ & $\operatorname{Dec}\left({ }^{\circ}\right)$ & $\operatorname{Inc}\left(^{\circ}\right)$ & $\operatorname{Temp}\left({ }^{\circ} \mathrm{C}\right)$ & Magnetic Polarity \\
\hline LKR1 & 25.1053 & 121.3262 & 81 & $2 \mathrm{~A}$ & 8.2 & 19.4 & 175.7 & -25.4 & $160-360$ & reversed \\
\hline LKR2 & 25.1033 & 121.3239 & 83 & $1 \mathrm{~A}$ & 92.7 & 20.9 & 182.1 & -32.1 & $25-640$ & reversed \\
\hline LKR3 $^{\#}$ & 25.0976 & 121.3355 & 108 & $4 \mathrm{~A}$ & 67.2 & 23.9 & 196.5 & -39.8 & $25-360$ & reversed \\
\hline $\mathrm{LKR}^{\#}{ }^{\#}$ & 25.0977 & 121.3353 & 109 & $4 \mathrm{~A}$ & 143.0 & 28.5 & 195.4 & -42.1 & $120-640$ & reversed \\
\hline LKR5 & 25.0984 & 121.3360 & 119 & $4 \mathrm{~A}$ & 22.8 & 24.7 & 171.2 & -36.3 & $25-360$ & reversed \\
\hline LKR6 & 25.0991 & 121.3363 & 135 & $3 \mathrm{~A}$ & 5.9 & 18.9 & 204.7 & -9.1 & $440-560$ & reversed \\
\hline LKR7 & 25.1016 & 121.3317 & 147 & $1 \mathrm{~A}$ & 4.6 & 8.9 & N/A & N/A & N/A & N/A \\
\hline JBR1 & 25.1206 & 121.3198 & 18 & $1 \mathrm{~A}$ & 9.5 & 17.3 & N/A & N/A & N/A & N/A \\
\hline JBR2 & 25.1197 & 121.3197 & 42 & $4 \mathrm{~A}$ & 26.8 & 22.8 & 175.2 & -50.8 & $160-400$ & reversed \\
\hline BDR1 & 25.1177 & 121.3394 & 40 & $3 \mathrm{~A}$ & 10.6 & 23.1 & 188.9 & -46.6 & $25-240$ & reversed \\
\hline $\mathrm{BDR}^{\prime \prime}$ & 25.1175 & 121.3419 & 61 & $5 \mathrm{~A}$ & 155.0 & 36.1 & 195.1 & -51.2 & $25-400$ & reversed \\
\hline ZSKR1 & 25.1155 & 121.3542 & 95 & $1 \mathrm{~A}$ & 33.0 & 21.7 & 160.2 & -32.9 & $25-400$ & reversed \\
\hline ZSKR2 & 25.1152 & 121.3541 & 103 & $4 \mathrm{~A}$ & 116.0 & 28.6 & 178.7 & -47.0 & $120-360$ & reversed \\
\hline ZSKR3 & 25.1142 & 121.3633 & 105 & $2 \mathrm{~A}$ & 22.4 & 20.2 & 205.7 & -46.6 & $25-400$ & reversed \\
\hline HKR $1^{\#}$ & 25.1247 & 121.3583 & 62 & $3 \mathrm{~A}$ & 48.5 & 19.4 & 181.9 & -28.8 & $120-360$ & reversed \\
\hline HKR2 & 25.1209 & 121.3606 & 115 & $1 \mathrm{~A}$ & 2.8 & 16.6 & N/A & N/A & N/A & N/A \\
\hline HSXR $^{\#}$ & 25.1155 & 121.3944 & 64 & $1 \mathrm{~A}$ & 82.5 & 22.0 & 188.7 & -33.9 & $25-400$ & Reversed \\
\hline HSXR2 & 25.1146 & 121.3942 & 78 & $3 \mathrm{~A}$ & 73.8 & 26.7 & 184.4 & -41.5 & $120-360$ & Reversed \\
\hline HSXR3 & 25.1104 & 121.3957 & 84 & $4 \mathrm{~A}$ & 3.6 & 18.1 & N/A & N/A & N/A & N/A \\
\hline
\end{tabular}

Note: \#: sites containing nannofossils; Lat. \& Long.: latitude and longitude; H: height.

$J_{0}$ and $\chi_{0}:$ intensity of NRM and low-field magnetic susceptibility at $25^{\circ} \mathrm{C}$.

Dec and Inc: declination and inclination of stable ChRM.

Temp: temperature range showing stable ChRM; N/A: not available. 


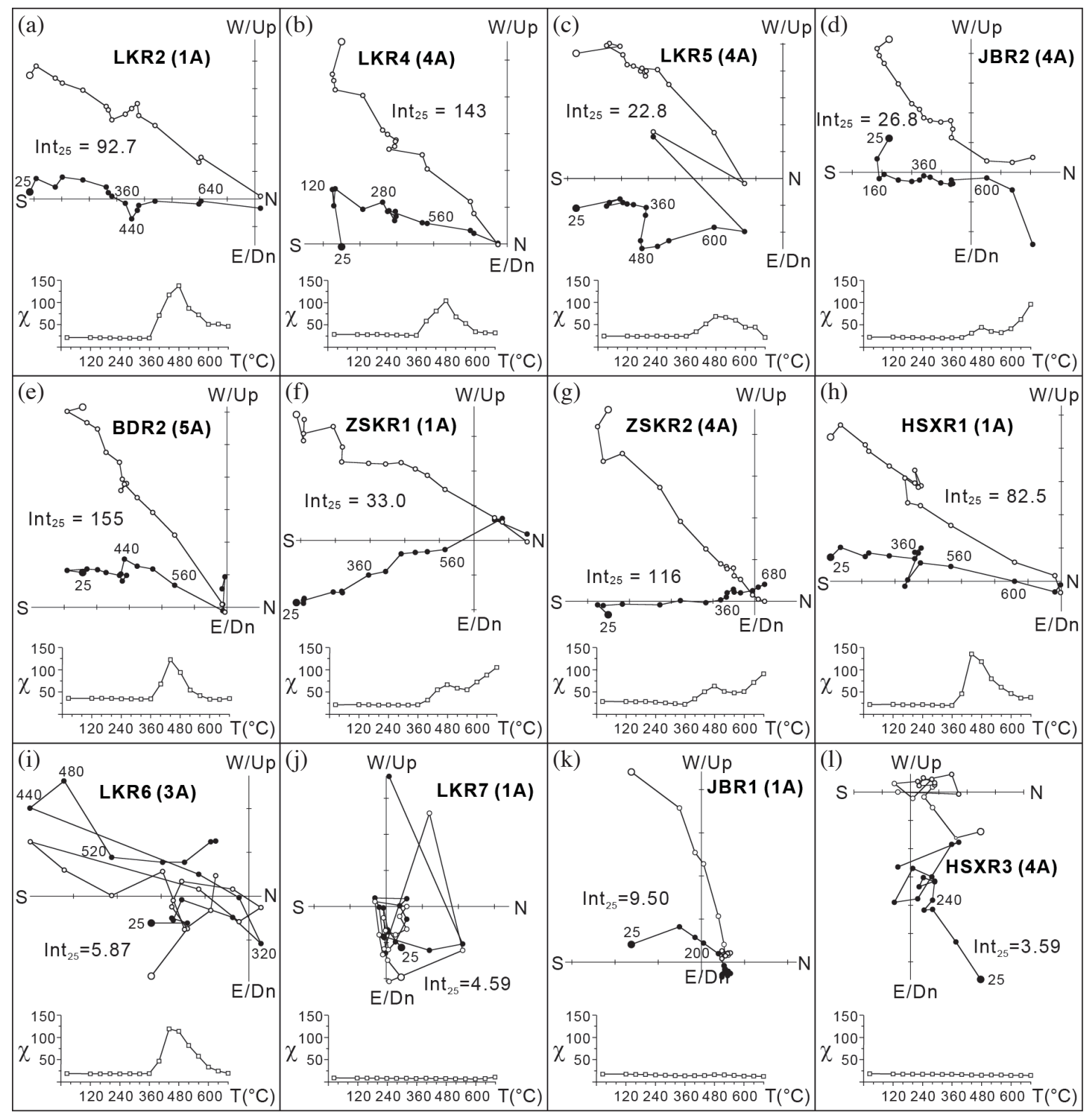

Fig. 4. Representative thermal demagnetization diagrams of specimens from various sites in the Tananwan Formation. Because of the flat-lying strata, no bedding correction was made on the specimens. Solid circles: horizontal projections (declinations); open circles: vertical projections (inclinations). Values next to the solid circles are temperatures. Intensity of $\mathrm{NRM}$ at $25^{\circ} \mathrm{C}\left(\mathrm{Int}_{25}, 10^{-3} \mathrm{Am}^{2}\right)$ of each specimen is indicated. Below each diagram is a plot of low-field magnetic susceptibility $\left(\chi, 10^{-6}\right)$ versus temperature. $(\mathrm{a}-\mathrm{h})$ Type $\mathrm{S}$ specimens with stable reversed ChRMs. $(\mathrm{i}-1) \mathrm{Type}$ $\mathrm{U}$ specimens showing unstable remanent magnetizations.

Changes in magnetic susceptibility during thermal demagnetization are also shown in Fig. 4. Samples with reversed magnetic polarity records, as illustrated in Figs. 4a - i, undergo remarkable changes in susceptibility at temperatures above $360^{\circ} \mathrm{C}$, whereas samples showing non-resolvable polarity records (Figs. $4 \mathrm{j}-1$ ) not only have low $\chi_{\mathrm{o}}$ (see Table 1) but also little change in $\chi$ during heating. The changes in $\chi$ above $360^{\circ} \mathrm{C}$ shown in Figs. $4 \mathrm{a}$ - i imply that the transformation from ferrous to ferric iron minerals has occurred during thermal demagnetization. Siderite is commonly present in the Tananwan Formation (Fig. 3) and can transform into other forms of magnetic minerals (i.e., secondary magnetite, maghemite, and hematite) during heating (Pan et al. 2000). Changes in susceptibility occurring above $360^{\circ} \mathrm{C}$ can be mainly caused by high-temperature oxidation of siderite. Because siderite is susceptible to weathering or oxidation, the presence of siderite in rocks also means that these rocks or samples are fresh and the primary depositional magnetite shown in Fig. 3 is still well-preserved. Therefore, the reversed magnetic polarities recorded in the siderite-bearing samples (Figs. 4a - i) are reliable. On the other hand, samples with low magnetic susceptibility (Figs. $4 \mathrm{j}-1$ and Table 1 ) must have experienced 
weathering to a large extent (see Figs. 2e - f), rendering their magnetic remanences unstable and polarities unclear.

\subsection{Calcareous Nannofossil Biostratigraphy}

Because of various depositional facies in nearshore environments, the strata in the Tananwan Formation com- monly or poorly may contain fossils. In this study, five sites (i.e., LKR3, LKR4, BDR2, HKR1, and HSXR1) with marine facies yield calcareous nannofossils with rather good preservation (Figs. 1a and 2a). Gephyrocapa spp. and Pseudoemiliania lacunosa are the dominant indigenous species in the nannofossil assemblage. Shown in micrographs $1-28$ of Fig. 5 are the representative Gephyrocapa spp. with sizes
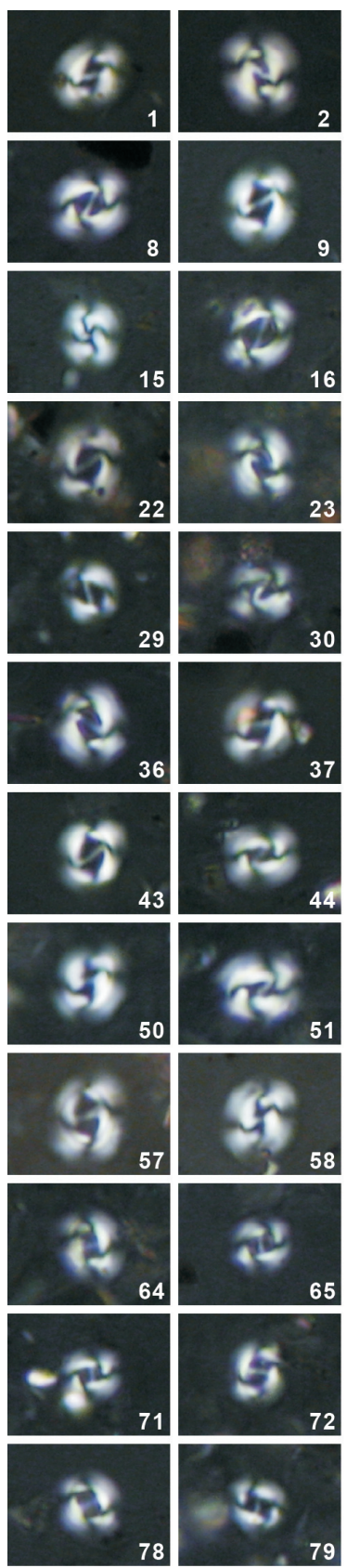
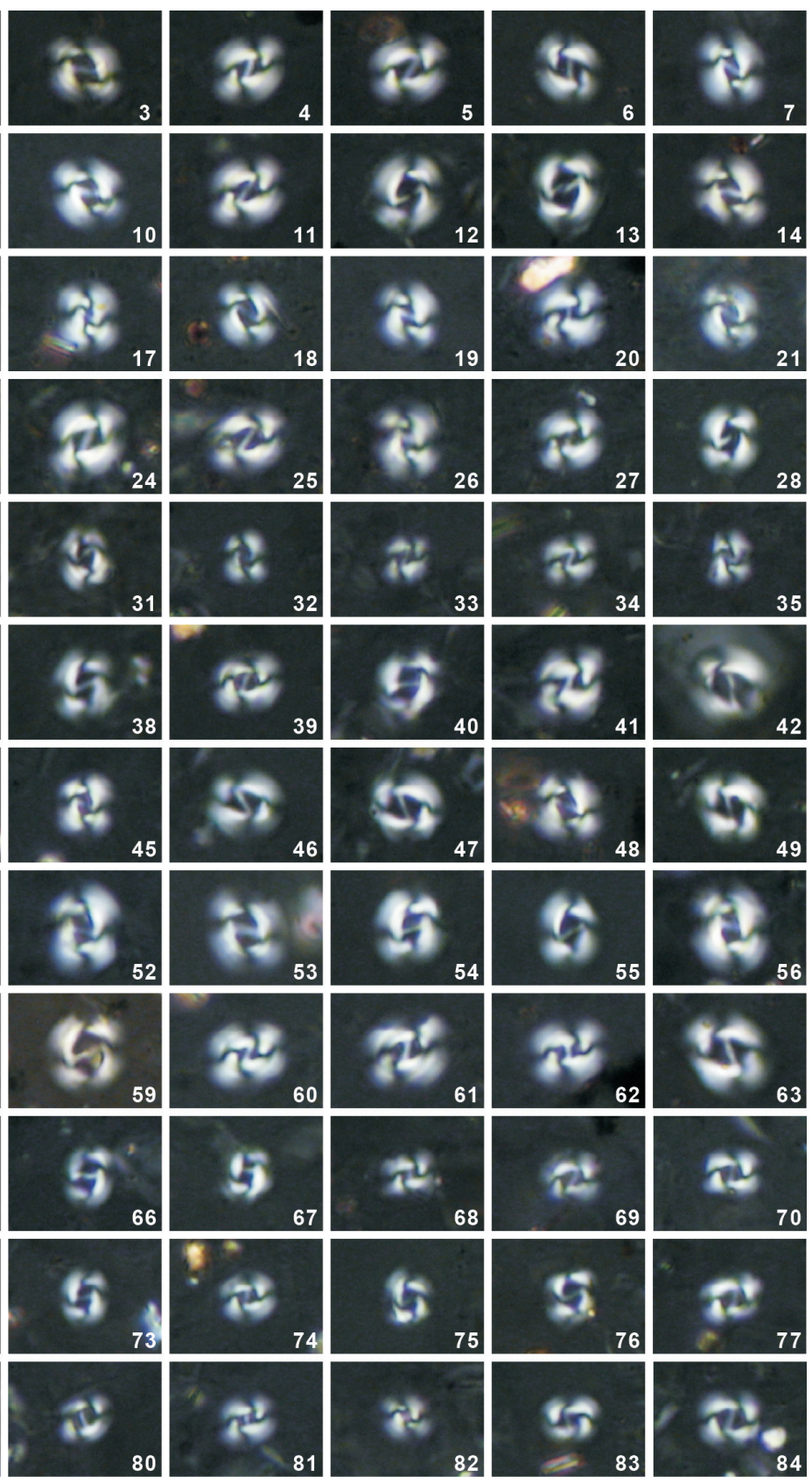

$5 \mu \mathrm{m}$

Fig. 5. Optical micrographs of Gephyrocapsa with sizes larger than $4 \mu \mathrm{m}$ from 5 sites (LKR3, LKR4, BDR2, HKR1, and HSXR1) in the Tananwan Formation and 8 sites (EJR1 - EJR8) in the Gutingkeng Formation. All graphs are shown at the same scale (scale bar $=5 \mu \mathrm{m}) .(1-7)$ LKR3; $(8-14)$ LKR4; (15 - 21) BDR2; (22 - 23) HKR1; (24 - 28) HSXR1; (29 - 35) EJR1 (the FAD of medium Gephyrocapsa, at 1.67 Ma); (36 - 42) EJR2; (43 - 49) EJR3; (50 - 56) EJR4; (57 - 63) EJR5 (near the disappearance datum of medium and large Gephyrocapsa, at 1.24 Ma); (64 - 70 ) EJR6 (the reappearance datum of medium Gephyrocapsa or FAD of Gephyrocapsa sp. 3, at $1.04 \mathrm{Ma})$; (71 - 77) EJR7; (78 - 84) EJR8. 
larger than $4 \mu \mathrm{m}$. Micrographs 29 - 84 in Fig. 5 illustrate the morphologic evolution of Gephyrocapa, showing the size variations of this genus at 8 sites in the Gutingkeng Formation along the EJR section (Fig. 1b) covering stratigraphic levels from the FAD of medium Gephyrocapsa (at $1.67 \mathrm{Ma}$ ), through the disappearance datum of large and medium $G e$ phyrocapsa (at $1.24 \mathrm{Ma}$ ), and up to the post-FAD of $G e$ phyrocapsa sp. 3 (i.e., younger than the reappearance datum of medium Gephyrocapsa, < $1.04 \mathrm{Ma}$ ) (Fig. 2b). It is clear from Fig. 5 that the sizes of Gephyrocapa spp. in the Tananwan Formation (micrographs 1 - 28) are almost equivalent to those (micrographs 36 - 63 in Fig. 5) of the four sites (i.e., EJR2 - EJR5) in the Gutingkeng Formation. SEM images of Gephyrocapa spp. from Sites LKR3 and EJR5 further reveal that some Gephyrocapsa specimens have sizes over $5.5 \mu \mathrm{m}$ (e.g., micrographs 1 - 3 and 13 - 14 in Fig. 6), indicating that large Gephyrocapsa spp. are present both in the Tananwan and Gutingkeng Formations. According to the consistent occurrence of large Gephyrocapsa, the age of the Tananwan Formation is estimated to be within 1.46 - 1.24 Ma, corresponding to a short, magnetically reversed interval in the Matuyama Epoch (Fig. 2b). The paleomagnetic results described here where only reversed magnetic polarities are preserved in the Tananwan Formation (Table 1) support this interpretation.

It should be noted that large and medium Gephyrocapsa in the Tananwan and Gutingkeng Formations with ages older than 1.24 Ma are characterized by a bridge that aligns diagonally to the short axis of placolith with either a wide open or a closed central area (micrographs 1 - 16 in Fig. 6). These characteristics can be also recognized with optical microscopy (micrographs 1 - 63 in Fig. 5). However, another type of medium Gephyrocapsa (i.e., Gephyrocapsa sp. 3) that occurs only after 1.04 Ma has a bridge nearly parallel to the short axis of placolith, as shown in the 3 younger sites of the Gutingkeng Formation (i.e., EJR6 - EJR8; see micrographs $64-68,71-72,78-82$ in Fig. 5 and micrographs $17-20$ in Fig. 6). In other words, the results of this study do not support the interpretation in Wei et al. (2009) that Gephyrocapsa sp. 3 is present in the Tananwan Formation.

\section{CONCLUSIONS}

From a reexamination of the nannofossil biostratigraphy
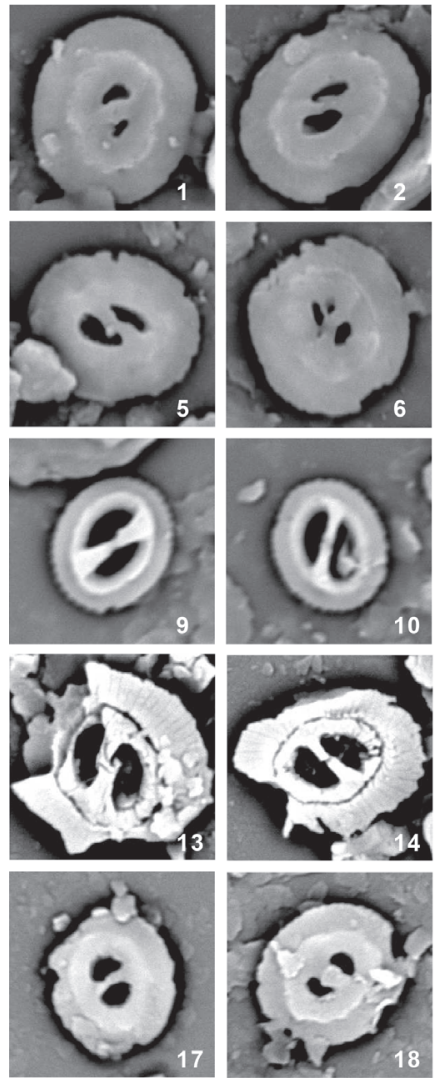
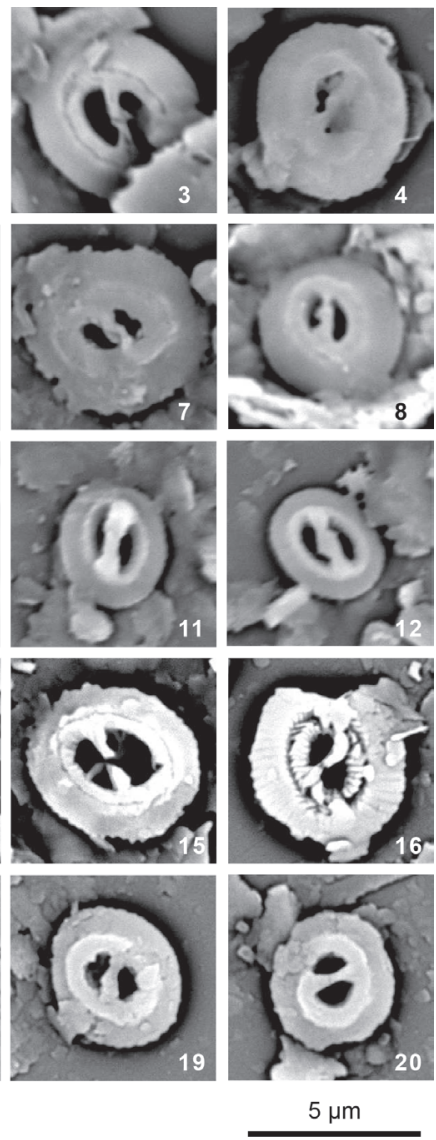

Fig. 6. Scanning electron micrographs of Gephyrocapsa with sizes larger than $4 \mu \mathrm{m}$ from Site LKR3 in the Tananwan Formation and Sites EJR5 and EJR6 in the Gutingkeng Formation. All graphs are shown at the same scale (scale bar $=5 \mu \mathrm{m}$ ). (1 - 12) LKR3; (13 - 16) EJR5 (at 1.24 Ma); $(17-20)$ EJR6 (at $1.04 \mathrm{Ma}$ ). It is noted that the alignment of bridge of Gephyrocapsa shown in micrographs $17-20$ is nearly parallel to the short axis of placolith (i.e., Gephyrocapsa sp. 3), while the alignment of others is diagonal. 
of the Tananwan Formation, it is suggested that the age of this formation should fall within the interval of $1.46-1.24 \mathrm{Ma}$, which is older than the $0.9-0.7 \mathrm{Ma}$ interval proposed by previous investigations (Shih 1991; Tseng et al. 1992; Wei et al. 2009). The time interval at 1.46-1.24 Ma suggests that the Tananwan Formation should record reversed magnetic polarities only. A revisit of the magnetostratigraphy lends support to the revision and rules out the existence in the formation of two normal polarity events (i.e., Jaramillo and Olduvai) proposed by Lee et al. (2002). This study also demonstrates that authigenic siderite is commonly present in this formation. Thus, interpretation of paleomagnetic data for the Tananwan Formation should be made with caution because siderite-bearing rocks may undergo more or less weathering and their rock magnetic properties will change accordingly.

Acknowledgements The author is grateful to Chao-Ming Chuang for field assistance and to Kuo-Hang Chen, ChunHung Lin and Chung-Yi Tseng for their help both in the field and the lab. Thanks are also due to Chih-An Huh for revising the first draft and to Wen-Rong Chi and Kai-Shuan Shea for reviewing the manuscript. This work is supported by the Institute of Earth Sciences, Academia Sinica and National Science Council grant NSC96-2116-M-001-013-MY2.

\section{REFERERCES}

Berggren, W. A., F. J. Hilgen, C. G. Langereis, D. V. Kent, J. D. Obradovich, I. Raffi, M. E. Raymo, and N. J. Shackleton, 1995: Late Neogene chronology: New perspectives in high-resolution stratigraphy. Geol. Soc. Am. Bull., 107, 1272-1287, doi: 10.1130/0016-7606(1 995) $107<1272:$ LNCNPI>2.3.CO;2. [Link]

Chen, P. H., C. Y. Huang, T. C. Huang, and L. P. Tsai, 1977: A study of the late Neogene marine sediments of the Chishan area, Taiwan: Paleomagnetic stratigraphy, biostratigraphy, and paleoclimate. Mem. Geol. Soc. China, 2, 169-190.

Chen, W. F. and L. S. Teng, 1990: Depositional environment of Quaternary deposits of the Linkou Tableland, northwestern Taiwan. Proc. Geol. Soc. China, 33, 39-63.

Chuang, C. M., W. F. Chen, and L. S. Teng, 2012: Depositional facies and environment of Tananwan Formation, Linkou Tableland. West. Pac. Earth Sci., 12, 127-156.

Dekkers, M. J., J. L. Mattéi, G. Fillion, and P. Rochette, 1989: Grain-size dependence of the magnetic behavior of pyrrhotite during its low-temperature transition at 34 K. Geophys. Res. Lett., 16, 855-858, doi: 10.1029/ GL016i008p00855. [Link]

Horng, C. S. and K. S. Shea, 2007: The Quaternary magnetobiostratigraphy of Taiwan and Penglai orogenic events. Spec. Publ. Cent. Geol. Sur., MOEA, 18, 5183.

Horng, C. S., M. Y. Lee, H. Pälike, K. Y. Wei, W. T. Liang,
Y. Iizuka, and M. Torii, 2002: Astronomically calibrated ages for geomagnetic reversals within the Matuyama chron. Earth Planets Space, 54, 679-690.

Housen, B. A., S. K. Banerjee, and B. M. Moskowitz, 1996: Low-temperature magnetic properties of siderite and magnetite in marine sediments. Geophys. Res. Lett., 23, 2843-2846, doi: 10.1029/96GL01197. [Link]

Lee, T. Q., Y. T. Lue, W. R. Chi, and L. S. Teng, 2002: Paleomagnetic study of the Kuanyinshan and Tanawan Formations, northern Taiwan. West. Pac. Earth Sci., 2, 27-36.

Lourens, L., F. Hilgen., N. J. Shackleton, J. Laskar, and D. Wilson, 2004: The Neogene Period. In: Gradstein, F. M., J. G. Ogg, and A. G. Smith (Eds.), A Geological Time Scale 2004, Cambridge University Press, Cambridge, 409-440.

Mozley, P. S., 1989: Relation between depositional environment and the elemental composition of early diagenetic siderite. Geology, 17, 704-706, doi: 10.1130/00917613(1989)017<0704:RBDEAT>2.3.CO;2. [Link]

Özdemir, Ö., D. J. Dunlop, and B. M. Moskowitz, 1993: The effect of oxidation on the Verwey transition in magnetite. Geophys. Res. Lett., 20, 1671-1674, doi: 10.1029/93GL01483. [Link]

Pan, Y., R. Zhu, S. K. Banerjee, J. Gill, and Q. Williams, 2000: Rock magnetic properties related to thermal treatment of siderite: Behavior and interpretation. J. Geophys. Res., 105, 783-794, doi: 10.1029/1999JB900358. [Link]

Pye, K., J. A. D. Dickson, N. Schiavon, M. L. Coleman, and M. Cox, 1990: Formation of siderite-Mg-calcite-iron sulphide concretions in intertidal marsh and sandflat sediments, north Norfolk, England. Sedimentology, 37, 325-343, doi: 10.1111/j.1365-3091.1990.tb00962.x. [Link]

Raffi, I., J. Backman, E. Fornaciari, H. Pälike, D. Rio, L. Lourens, and F. Hilgen, 2006: A review of calcareous nannofossil astrobiochronology encompassing the past 25 million years. Quat. Sci. Rev., 25, 3113-3137, doi: 10.1016/j.quascirev.2006.07.007. [Link]

Rio, D., 1982: The fossil distribution of coccolithophore genus Gephyrocapsa Kamptner and related Plio-Pleistocene chronostratigraphic problems. Init. Repts. DSDP, 68, 325-343, doi: 10.2973/dsdp.proc.68.109.1982. [Link]

Rio D., R. Sprovieri, and I. Raffi, 1984: Calcareous plankton biostratigraphy and biochronology of the PlioceneLower Pleistocene succession of the Capo Rossello area, Sicily. Mar. Micropaleontol., 9, 135-180, doi: 10.1016/0377-8398(84)90008-2. [Link]

Rio, D., I. Raffi, and G. Villa, 1990: Pliocene-Pleistocene calcareous nannofossil distribution patterns in the western Mediterranean. Proc. ODP. Sci. Results, 107, 513533, doi: 10.2973/odp.proc.sr.107.164.1990. [Link] 
Rochette, P., G. Fillion, J. L. Mattéi, and M. J. Dekkers, 1990: Magnetic transition at 30-34 $\mathrm{K}_{\text {in }} \mathrm{Fe}_{7} \mathrm{~S}_{8}$ : Insight into a widespread occurrence of pyrrhotite in rocks. Earth Planet. Sci. Lett., 98, 319-328.

Shea, K. S. and C. S. Horng, 1999: Recognition of the Pliocene-Pleistocene boundary based on Pulleniatina coiling change: A case study of the Erhjen-chi section, southwestern Taiwan. Quat. Sci., 6, 549-555.

Shih, T. S., 1991: A study of ESR dating on mollusk fossils. Master Thesis, National Taiwan University, Taiwan, $168 \mathrm{pp}$.

Tseng, M. H., P. M. Liew, W. R. Chi, and T. S. Shih, 1992:
Pollen analysis of the Tananwan Formation, Northern Taiwan. J. Geol. Soc. China, 35, 247-259.

Verwey, E. J. W., 1939: Electronic conduction of magnetite $\left(\mathrm{Fe}_{3} \mathrm{O}_{4}\right)$ and its transition point at low temperatures. Nature, 144, 327-328, doi: 10.1038/144327b0. [Link]

Wei, K. Y., C. K. Zhuang, and C. M. Zhuang, 2009: Biochronology study of the Tananwan Formation: A revisit. Spec. Publ. Cent. Geol. Surv., MOEA, 22, 149-164.

Wei, W., 1993: Calibration of upper Pliocene-lower Pleistocene nannofossil events with oxygen isotope stratigraphy. Paleoceanography, 8, 85-99, doi: 10.1029/92PA02504. [Link] 